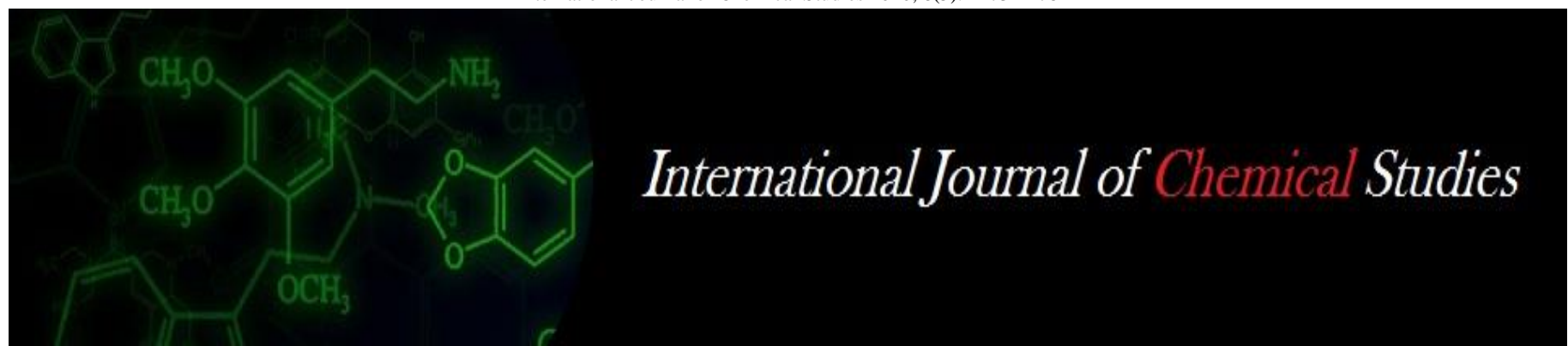

P-ISSN: 2349-8528

E-ISSN: 2321-4902

www.chemijournal.com

IJCS 2020; 8(5): 1273-1278

(C) 2020 IJCS

Received: 22-06-2020

Accepted: 10-08-2020

Shiv Kumar Patel

RAK College of Agriculture,

RVSKVV, Gwalior, Sehore,

Madhya Pradesh, India

\section{Anurag Gupta}

School of Studies in Statistics,

Vikram University Ujjain,

Madhya Pradesh, India

Shalini Chakraborty

Fruit Research Station,

RVSKVV, Gwalior, Entkhedi,

Bhopal, Madhya Pradesh, India
Corresponding Author:

Shiv Kumar Patel

RAK College of Agriculture,

RVSKVV, Gwalior, Sehore,

Madhya Pradesh, India

\section{Quality assessment of differently dried garlic (Allium Sativum L.) and storage studies of garlic powder with different packaging conditions}

\author{
Shiv Kumar Patel, Anurag Gupta and Shalini Chakraborty
}

DOI: https://doi.org/10.22271/chemi.2020.v8.i5r.10477

\begin{abstract}
Drying of garlic (var. Yamuna safed-3, G-282) was carried out in shade drying (room temperature $32^{\circ} \mathrm{C}$ ), oven drying $\left(60 \pm 5^{\circ} \mathrm{C}, 8-10 \mathrm{~h}\right)$, microwave drying $(800 \mathrm{~W}, 7$ minute), and; solar drying $(16-18 \mathrm{~h})$. Garlic cloves were blanched in boiling water for $10-15$ seconds followed by dipping in 0.2 percent potassium meta bi sulphite (KMS) for five minutes at room temperature, This sample was called a treated sample. The treated samples and untreated samples were subjected to different drying techniques followed by evaluation in terms of product recovery, rehydration ratio, cutting strength, colour, titratable acidity and ascorbic acid content. Full factorial completely randomized design was adopted for the experiments. It was observed that across all the responses shade drying and there was no significant $(p<0.05)$ effect of solar drying, while treated and untreated rendered significant $(p<0.05)$ difference to the responses. Communized dried garlic cloves were evaluated for quality parameters (ascorbic acid, acidity and Colour, taste, flavor and overall acceptability) and was found best with treated in shade drying condition. Microbiological parameters viz., total viable fungal colony in different packaging material (LDPE, PE, multilayered) was evaluated for garlic powder stored for a period of 60 days. Multilayered packaging for garlic powder was found to be the most acceptable and safe.
\end{abstract}

Keywords: Garlic clove, garlic-powder, microbiology, packaging, quality, texture

\section{Introduction}

Garlic (Allium Sativum L.) is a member of the Alliaceae family. It is cultivated in both temperate and tropical climates. Garlic is originated from Central Asia and Southern Europe, especially the Mediterranean region (Thompson and Kelly, 1957) ${ }^{[19]}$.

Garlic is one of the main spice crop that has been harvested from December to March. Garlics flavour and pungency give Indian dishes a particular taste. Nowadays, garlic is used for its flavours, aromas and tastes produced domestically or in agriculture, as base for a variety of food production processes, dehydration and pickling. Powder made from dried or dried garlic cuts may be used to prepare Indian dishes separated from the use of it as a flavour, the improvement of quality retention of dried products by altering drying process and pretreatment has been a research goal. In this respect, novel drying techniques including shade drying, oven drying, microwave and solar drying of garlic have been the subject of extensive research. In this study the effects of above four types of drying i.e. shade drying, oven drying, microwave and solar drying on the quality of garlic will be studied and compared.

Taking this solution in to consideration this study has been carried out with the given objectives- To assess physical parameters of garlic. To assess the quality parameters of garlic powder dried using different techniques. To study effect of packaging material on shelf life of packed garlic powder.

\section{Materials and Methods}

Raw materials: The freshly picked garlic was used under this experiment. Yamuna safed-3 (G-282) garlic was obtained from R.A.K. College of Agriculture Sehore (M.P.). Immature bulbs, diseased and damaged bulbs were identified and dropped then fresh garlic products were chosen for the experiment. For different treatments of fresh garlic bulbs, a sample of 100 g. each was weighed. Dry garlic cloves were grinded in a domestic grinder to make the powder. 
Pre-treatments: For the improvement in colour and shelf life, the garlic clove was bleached in boiling water for 10-15 seconds and then immersed in 0.2 per cent KMS solution for 5 minutes at room temperature. One sample was not given the blanching and sulphiting treatments and it was treated as control (One treated and one untreated sample).

Drying methods: Treated garlic cloves were dried using four distinct drying methods (i) Shade drying, $100 \mathrm{~g}$ garlic cloves were dried in shade at room temperature; (ii) Oven drying, $100 \mathrm{~g}$ garlic clove was subjected to a dryer temperature of $60 \pm 5 \mathrm{oC}$ and drying was carried for a time period of 8-10 h; (iii) Microwave drying, $100 \mathrm{~g}$ garlic clove were dried at a power and time of $800 \mathrm{~W}$ and 7 minutes, respectively; (iv) Solar drying, the temperature of the hot air solar dryer was $54 \mathrm{oC}$, garlic clove were kept in it for 16-18 h. The dryer is an in-house production of ICAR - Central Institute of Agricultural Engineering (CIAE) Bhopal, (M.P.).The garlic clove obtained after drying were pulverized to obtain Garlic powder. Dried slice was converted into powder with the help of domestic grinder for 2 minutes. The powder was allowed to cool at room temperature before storage.

Product recovery percent: The weight of fresh garlic was noted after completing of the drying procedure and recovery percentage of dried clove was determined utilizing the accompanying equation

Recovery $(\%)=\frac{\text { Weight of dried product }(\mathrm{g})}{\text { Weight of fresh products }(\mathrm{g})} \times 100$

Rehydration ratio: Rehydration ratio of dried garlic clove was estimated as per the method described by Ranganna, (1986) ${ }^{[17]}$. Several trail runs were carried out to standardize the experimental conditions for estimation time of rehydration. Dry garlic (WD = $2 \mathrm{~g}$ ) was put in boiling water for 25 minutes and the contents were passed through whattman No. 4 filter paper. The rehydrated garlic sample was weighed and the weight recorded as WR. The rehydration ratio (RR) was calculated using the following equation (Ranganna, 1986) ${ }^{[17]}$.

Reydration rat

$$
\text { Reydration ratio }(R R)=\frac{W_{R}}{W_{D}}
$$

Cutting strength: It was determined instrumentally by using a texture analyzer (TA XT2i, Stable Microsystems, Surrey, England) with Texture Expert Exceed 2.46 version software. The cutting strength of garlic clove was recorded by using the knife blade probe at test speed: $0.5 \mathrm{~mm} / \mathrm{s}$; distance: $10 \mathrm{~mm}$; load cell: $250 \mathrm{~kg}$. Cutting strength was recorded as the peak force $(\mathrm{N})$ required snapping the material that was placed below the downward moving probe of the texture analyses.

Colour: The colour of dried garlic changes because of the non-enzymatic browning that occurs during the drying process. Color is one of the important parameters that indicate the economic value of the product. The prime purpose was to have an idea of a comparative change in the colour of the dried garlic powder. Colour was determined using the Hunter Lab Miniscan XE plus Colorimeter (Hunter 1975). Samples were placed on the measure head of XE plus Colorimeter and measurements of colour were performed for all prepared samples. A standard white colour was used for calibration and experiments were replicated three times for statistical purpose. Total colour change between fresh garlic sample $\left(\mathrm{L} \_0^{\wedge *}, \mathrm{a} \_0^{\wedge *}, \mathrm{~b} \_0^{\wedge *}\right)$ and dried garlic samples $\left(\mathrm{L}^{\wedge *}, \mathrm{a}^{\wedge *}\right.$ and $\left.\mathrm{b}^{\wedge *}\right)$ was determined according to Equation

$$
\Delta \mathbf{E}=\sqrt{\left.\left[\left(\mathrm{L}_{0}^{*}\right)-\mathrm{L}^{*}\right)+\left(\mathrm{a}_{0}^{*}-\mathrm{a}^{*}\right)+\left(\mathrm{b}_{0}^{*}+\mathrm{b}^{*}\right)\right]}
$$

Samples were placed on the measuring head of the Chrome Meter and colour measurements were taken for all samples prepared. Standard white colour was used for calibration and the experiments were replicated five times for statistical purposes.

Where, $\Delta \mathrm{L}, \Delta \mathrm{a}$ and $\Delta \mathrm{b}$ are the color difference values for ' $\mathrm{L}$ ' (lightness indicator), ' $a$ ' (greenness to redness indicator) and 'b' (blueness to yellowness).

Acidity: In order to determine the acidity, add a few drops of water to the 5-10 g sample, mix thoroughly. Subsequently, titrate the sample using phenolphthalein as an indicator against standard $0.1 \mathrm{~N}$ sodium hydroxide. The presence of the light pink colour indicates the final phase. The acidity was calculated using the given formula (AOAC, 1988).

$\operatorname{Acidity}(\%)=\frac{1 \times \text { Eq.Wt.of acid x Normality of NaOH x Titer }}{10 \times \text { Weight of sample }} \times 100$

Principle: Ascorbic acid reduces the colouring of 2, 6dichlorophenol indophenols to a colourless leuko-base. Ascorbic acid is oxidised to dehydrate ascorbic acid. Although the dye is a blue coloured compound, the final phase is the appearance of a pink colour. The colour of the dye is pink in the acid medium. Oxalic acid is used as a titrating agent.

\section{Materials}

1. $4 \%$ concentrated Oxalic acid

2. Dye solution: $42 \mathrm{mg}$ sodium bicarbonate was weighed into a small amount of distilled water. $52 \mathrm{mg} \mathrm{2,6-}$ dichlorophenol indophenols had been dissolved and had been made up to $200 \mathrm{ml}$ of distilled water.

3. Standard solution: $100 \mathrm{mg}$ of ascorbic acid in $100 \mathrm{ml}$ of 4 percent of oxalic acid solution in a standard flask $(1 \mathrm{mg} /$ $\mathrm{ml})$.

4. Working standard: $10 \mathrm{ml}$ stock solution was diluted in $1000 \mathrm{ml}$ with oxalic acid 4 percent. The working standard concentration was $100 \mu \mathrm{g} / \mathrm{ml}$.

Procedure: Poured $5 \mathrm{ml}$ working standard solution into a 100 $\mathrm{ml}$ conical flask. $10 \mathrm{ml}$ of 4 percent oxalic acid was added and titrate against the dye $(\mathrm{V} 1 \mathrm{ml})$. The end point was the appearance of a pink colour, which lasted for a few minutes. The amount of dye consumed was equivalent to that of ascorbic acid.

The sample (0.5-5g depending on the sample) was extracted in 4 per cent oxalic acid and made up to a known volume $(100 \mathrm{ml})$ and centrifuged. $5 \mathrm{ml}$ of this supernatant was taken, $10 \mathrm{ml}$ of 4 percent oxalic acid was added and dye titrated (V2ml)

\section{Calculation}

Ascorbic acid mg/100g) $=\frac{0.5 \times \mathrm{V} 2 \times 100 \mathrm{ml} \times 100}{\mathrm{~V} 1 \times 5 \mathrm{ml} \times \text { Weight of sample }} \times 100$ 
Where, V1 is the dye volume; V2 is the titre volume of the dye, ml Microbial study by standard plate count method (SPC): Approximately $23.5 \mathrm{~g}$ of potato dextrose agar (PDA) was taken in a conical flask and $1000 \mathrm{ml}$ of distilled water was added. It was heated in steam at $12^{\circ} \mathrm{C}$ below 15 psi atmospheric pressure for 15 minutes and then cooled to about 40o C. A series of dilution were made using $9 \mathrm{ml}$ blanks.

1. The initial $1 / 10$ dilution (1 $\mathrm{g}$ sample in $9 \mathrm{ml}$ distil water) was performed

2. This was mixed well in a vortex mixer. It becomes 10-1 time's dilution.

3. $1 \mathrm{ml}$ was taken and added to the next tube containing 9 $\mathrm{ml}$ ringer Solution and mixed well. It became 10-2 time's dilution
4. $1 \mathrm{ml}$ was taken and added to next tube containing $9 \mathrm{ml}$ ringer solution and mixed well. It then becomes 10-3 time's dilution.

The dilution was made up to 10-6 times in this way. Six sterilized petri dishes were taken, each of which was marked with a dilution number. Approximately 15-20 ml of PDA was taken in each petridish. $1 \mathrm{ml}$ of the diluted sample was then pipetted into each of these sterile Petri dishes. The contents of the plates were well mixed by swirling on a flat surface. Each dilution was placed in a triplicate. After solidification of the media the plates were kept in incubator inversely and incubated at $25^{\circ} \mathrm{C}$ for 48 to $96 \mathrm{hrs}$.

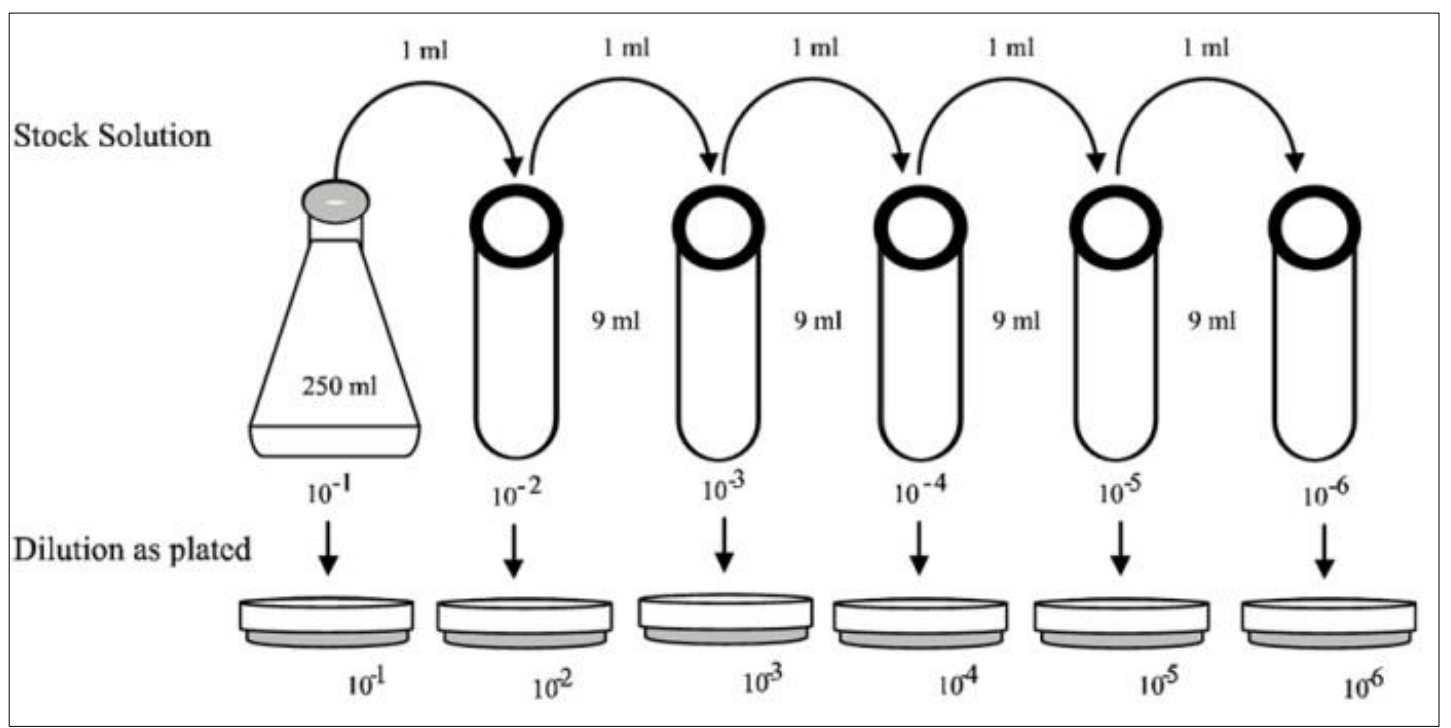

Fig 1: Pictorial representation of dilution process

After incubation, the petridishes were removed and checked for specified time. Plates containing segregated, overlapping and confusing colonies have been avoided. Plates containing bright, cleared and countable colonies were selected for easy settlement counting.

Number of colony forming unit $\frac{\mathrm{cfu}}{\mathrm{g}}$ or $\mathrm{ml} .=$ average $\frac{\mathrm{cfu}}{\text { plate }} \times$ dilution factor

Sensory analysis: Dry garlic cloves were ground in a grinder to make fine powder. The sensory quality of the powders developed in terms of colour, flavour and texture was assessed by panelists using a 9-point hedonic scale (Lawless and Klein, 1999).

Packaging material studies on shelf life of packed garlic powder: In the present study, the microbial population in garlic powder samples in different packaging material by shade drying, oven drying, and microwave drying and solar drying methods were assessed. The total fungal count in fresh and packed garlic powder ( $2 \mathrm{~g})$ at 0, 30, 60 days was analyzed in three different packaging materials, polyethylene (PE) 100 gauge, multilayered (ML) 300 gauge and low-density polyethylene (LDPE) 200 gauge.

Experimental design: The design of the experiment can be understood from Table-1. It enumerates the recording of the various parameters of garlic bulbs, garlic clove and garlic powder.

\section{Results and Discussion}

Physical-chemical parameters of fresh garlic: The physical parameters of fresh garlic viz., bulb weight (g), number of bulbs/Kg, number of cloves per bulb, cloves weight before peeling $(\mathrm{g})$, cloves weight after peeling $(\mathrm{g})$, moisture content $(\%$, wb), ascorbic acid (mg/100 g), acidity (\%), total viable fungal were estimated by standard methods as described earlier, parameters of fresh garlic are shown in Table-2. The physic-chemical parameter of fresh samples viz., the bulb weight $(24 \mathrm{~g} \pm 3.41)$, number of bulbs $(53 \pm 5.21 / \mathrm{kg})$, number of cloves $(17 \pm 4.33 / \mathrm{bulb})$, cloves weight before peeling (1. $68 \pm 2.01 \mathrm{~g})$, cloves weight after peeling $(1.28 \pm 2.13 \mathrm{~g})$, initial moisture content $(67.60 \% \pm 1.9$,wetbasis. $)$ acidity $(2.57 \% \pm 099)$ and ascorbic acid $(11.51 \mathrm{mg} / 100 \mathrm{~g})$, Total viable fungal (Nil), cutting strength $(7.25 \pm 3.61 \mathrm{~N})$ were recorded before drying. Similar results were reported by Casado et al. (2004) ${ }^{[7]}$. Madamba et al. (1996) ${ }^{[13]}$, Choudhury (1979) and Flores (1954) ${ }^{[9]}$. They found that the moisture content of freshly peeled garlic cloves ranged from (60-80 per cent, wb) to ( 7.8 per cent to 20.4 per cent, $\mathrm{db}$ ).

Physical parameters of dried garlic clove: In the present study product recovery (per cent) differed significantly with respect to the drying technique and treatments. The mean value of product recovery varied from 29.70 to 33.10 per cent in treated sample and 30.96 to 35.20 per cent in untreated sample and the mean value of weight loss was 66.9 to 70.4 in treated and 64.8 to 68.60 in untreated sample across all drying techniques. Converse of product recovery is weight loss 
(g/100g), it differed significantly with respect to the drying technique and among treatments (treated and untreated). The maximum product recovery (\%) and minimum weight loss were observed in shade drying and the minimum, product recovery (\%) and maximum weight loss observed in oven drying. The minimum product recovery (\%) and maximum weight loss in oven drying is due to fact that sample was kept for long time on increased temperature so uniform drying of clove occur. The results reported are supported by Baysal et

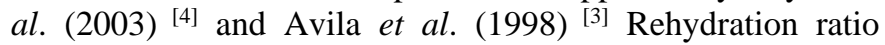
differed significantly with respect to the drying technique and treatments. KMS treatment resulted in higher value of rehydration ratio. In the present value of rehydration ratio range in treated sample was 2.06 to 2.66 and untreated sample it was 2.0 to 2.33. Rehydration ratio was higher in oven drying and lower shade drying followed by other drying method in the experiment. This might be due to fact that highest moisture content in shade drying so lowest absorption of water by shade drying garlic clove. Similar results has been reported by Mayer and Sere (2004) ${ }^{[14]}$ and Abasi et al., (2008) for dehydrated garlic clove.

The highest cutting strength $(56.41 \mathrm{~N})$ was recorded in solar drying under treated, whereas the lowest cutting strength $(29.65 \mathrm{~N})$ was recorded in microwave drying under untreated This is due to the fact that there is high moisture content in solar drying. So highest moisture content makes the sample tender and sticky and higher heat surface temperature and longer drying time in microwave drying cause fragility and brittleness. During drying process, influenced by high temperatures, cell walls undergo modifications in terms of their macrostructure and microstructure properties (Kunzen et al., 1999).

Table 1: Plan of experiments for determination of various parameters

\begin{tabular}{|c|c|c|}
\hline \multirow[t]{3}{*}{ Fresh garlic clove } & Physical parameter & $\begin{array}{l}\text { Bulb weight of sample }(\mathrm{g}) \\
\text { Number of bulbs/kg } \\
\text { Number of cloves per bulb } \\
\text { cloves weight before peeling }(\mathrm{g}) \\
\text { cloves weight after peeling }(\mathrm{g}) \\
\text { Moisture content }(\%, \mathrm{wb}) \\
\text { cutting strength }(\mathrm{N})\end{array}$ \\
\hline & Quality parameter & $\begin{array}{c}\text { Acidity }(\%) \\
\text { Ascorbic acid (mg/100 g) }\end{array}$ \\
\hline & Microbiological parameter & Microbial count \\
\hline Dried garlic clove & Physical parameter & $\begin{array}{c}\text { Final weight }(\mathrm{g}) \\
\text { Loss in weight }(\mathrm{g}) \\
\text { Product recovery percent } \\
\text { Rehydration Ratio } \\
\text { cutting strength }(\mathrm{N})\end{array}$ \\
\hline \multirow{4}{*}{ Dried garlic powder } & Physical parameter & $\begin{array}{l}\text { Moisture content }(\%, \mathrm{db}) \\
\text { Colour measurement }\end{array}$ \\
\hline & Quality parameter & $\begin{array}{c}\text { Acidity }(\%) \\
\text { Ascorbic acid (mg/100 g) }\end{array}$ \\
\hline & Sensory evaluation & Colour, taste, flavor and overall acceptability \\
\hline & Microbiological parameter & Microbial count \\
\hline
\end{tabular}

Table 2: Physical and Quality parameters of fresh garlic cv. G-282

\begin{tabular}{|c|c|c|}
\hline S. No. & Parameters & Average value \pm SD \\
\hline 1. & Bulb weight of sample & $24 \mathrm{~g} \pm 3.41$ \\
\hline 2. & Number of bulbs/kg & $53 \pm 5.21$ \\
\hline 3. & Number of cloves per bulb & $17 \pm 4.33$ \\
\hline 4. & Weight of cloves before peeling & $1.68 \mathrm{~g} \pm 2.01$ \\
\hline 5. & Weight of cloves after peeling & $1.28 \mathrm{~g} \pm 2.13$ \\
\hline 6. & Moisture content, wb & $67.60 \% \pm 1.9$ \\
\hline 7 & Ascorbic acid & $11.51 \mathrm{mg} / 100 \mathrm{~g} \pm 2.11$ \\
\hline 8 & Acidity & $2.57 \% \pm 0.99$ \\
\hline 9 & cutting strength & $7.25 \mathrm{~N} \pm 3.61$ \\
\hline 10. & Total number of fungal $(\mathrm{cfu} / \mathrm{g})$ & $\mathrm{Nil}$ \\
\hline
\end{tabular}

\# Values are average of 10 replications.

Physical parameters of garlic powder: Moisture content differed significantly with respect to the drying techniques and among sample (treated and untreated) it ranged from 3.25 to 3.47 per cent in treated sample and 3.52 to 3.90 per cent in untreated sample. The final moisture content is maximum in shade drying method under untreated and minimum in oven drying under treated. This is due the fact that it takes long time on room temperature for drying in shade drying techniques and moisture content decreases rapidly with increased temperature till long time in oven drying techniques. Similar findings for moisture content in the oven dried garlic powder have been reported earlier by Rathor and Mathur (2001) ${ }^{[16]}$ and Bandre et al. (2016) in their experiment of determining the moisture content of garlic powder. Total colour change (dried powder and fresh clove sample) $\Delta \mathrm{E}$ of garlic samples was between 35.76 and 37.09. The lowest Total colour change $(\Delta \mathrm{E})$ was obtained in shade drying conditions. Since these conditions include room temperature and long drying time, it was rather expected for sample to have lower total colour change $(\Delta \mathrm{E})$. The highest total colour change $(\Delta \mathrm{E})$ was observed in microwave drying, $800 \mathrm{~W}$ powder high temperatures and short drying time was significant which caused darkening of the sample. These results are significantly comparing to results observed in this study. Further, results in this study are more similar with results found in study by Figiel (2009) ${ }^{[8]}$.

The titratable acidity varied between 0.52 to 0.69 per cent in treated sample and 0.61 to 0.76 per cent in untreated sample. Maximum acidity was in shade dried

Samples and minimum was in sun dried samples. This is due to low quality effect in shade drying techniques because of exposing the sample for longer period in the shade (approximately 8-9 days). Related studies have been reported by Casado et al. (2004) ${ }^{[7]}$, Pruthi et al. (2001) ${ }^{[15]}$ and Flores (1954) ${ }^{[9]}$. Sharma (1993) ${ }^{[18]}$ has also reported lower values for acidity and ascorbic acid in shade dried garlic powder.

The ascorbic acid content of fresh garlic vitamin-C content was $11.51 \mathrm{mg} / 100 \mathrm{~g}$. garlic powder dried using different drying methods reported that ascorbic acid content of 
dehydrated garlic ranged from 4.02 to 5.96 in treated condition and 4.52 to $6.60 \mathrm{mg} / 100 \mathrm{~g}$ in untreated condition dried in four dehydration techniques. Retention of vitamin $\mathrm{C}$ was maximum in case of shade drying, $10.64 \mathrm{mg} / 100 \mathrm{~g}$ for treated sample. Shade drying did not involve high temperature and vitamin $\mathrm{C}$ is temperature sensitive. Drying at low temperature in shade drying resulted in high vitamin $\mathrm{C}$ content in the dried product.

Garlic powders prepared using different drying techniques were found to be acceptable by the panelists. A panel of 10 judges evaluated the overall acceptability of the treatment by 9-point hedonic scale the highest Colour, taste, flavor and overall acceptability score was recorded in shade drying under treated whereas the lowest overall acceptability score was recorded in microwave drying under treated.

Microbiology of packed garlic powder: The total number of fungal count drying and storage period was maximum in untreated sample as compared to Treated sample. This is due to the fact was treated by Blanching and Sulphiting.
Blanching inactivates enzymes, reduces microorganisms and displaces trapped air in plant tissues. It is also observed that treated and untreated sample stored in PE (polyethylene) as compared to Multilayered and LDPE (Low density polyethylene) shows maximum number of total fungal count and minimum number of total fungal count found in multilayered packaging. The reason may due be there in more water migration through PE (polyethylene) compared to Multilayered and LDPE (Low density polyethylene) which supports fungal growth. It depends on permeability, thickness and temperature. It is also seen in different drying techniques that shade drying as compared to oven drying, microwave drying, solar drying shows maximum number of total fungal count in different sample and packaging material. The reason may due to high moisture content and takes long time on room temperature for drying in shade drying techniques. Show minimum number of total fungal count found in oven drying techniques. Reason may due to low moisture content because garlic sample was dried on high temperature till long time in oven drying techniques.

Table 3: Effect of treatment and drying techniques on various parameters of dried garlic clove

\begin{tabular}{|c|c|c|c|c|c|}
\hline Parameter & Treatment & Shade drying & Oven drying & Microwave drying & Solar drying \\
\hline \multirow{2}{*}{ Product recovery (per cent) } & $\mathrm{T}_{1}$ & $33.10 \pm 1.37$ & $29.70 \pm 1.27$ & $30.16 \pm 0.04$ & $31.93 \pm .2 .21$ \\
\cline { 2 - 6 } & $\mathrm{T}_{2}$ & $35.20 \pm 2.62$ & $30.96 \pm 2.04$ & $31.40 \pm 1.27$ & $32.96 \pm 2.51$ \\
\hline \multirow{2}{*}{ Rehydration ratio } & $\mathrm{T}_{1}$ & $2.13 \pm 0.11$ & $2.8 \pm 0.2$ & $2.53 \pm 0.11$ & $2.66 \pm 0.11$ \\
\cline { 2 - 6 } & $\mathrm{T}_{2}$ & $2.06 \pm 0.11$ & $2.4 \pm 0.2$ & $2.26 \pm 0.11$ & $2.2 \pm 0.2$ \\
\hline \multirow{2}{*}{ Cutting strength (N) } & $\mathrm{T}_{1}$ & $54.36 \pm 11.91$ & $31.33 \pm 8.45$ & $29.65 \pm 7.27$ & $40.74 \pm 6.75$ \\
\cline { 2 - 6 } & $\mathrm{T}_{2}$ & $49.38 \pm 5.99$ & $56.38 \pm 9.90$ & $35.32 \pm 11.74$ & $56.38 \pm 9.90$ \\
\hline
\end{tabular}

$\mathrm{T}_{1}$ : Treated, $\mathrm{T}_{2}$ : Untreated; reported values are an average of 3 replications

Values given in the Parenthesis depicts the standard deviation.

Significant value if the value is less than $=0.1 \%$ (Significant at $p<10$ per cent) than value is Significant. If the value is less than $=0.05 \%$ (Significant at $p<5$ per cent) than value is Significant.

Table 4: Effect of treatments and drying techniques on various parameters of garlic powder

\begin{tabular}{|c|c|c|c|c|c|}
\hline Parameter & Treatment & Shade drying & Oven drying & Microwave drying & Solar drying \\
\hline \multirow{2}{*}{ Final moisture (per cent) } & $\mathrm{T}_{1}$ & $3.47 \pm 0.07$ & $3.25 \pm 0.06$ & $3.30 \pm 0.08$ & $3.35 \pm 0.05$ \\
\cline { 2 - 6 } & $\mathrm{T}_{2}$ & $3.90 \pm 0.04$ & $3.48 \pm 0.06$ & $3.52 \pm 0.05$ & $3.71 \pm 0.05$ \\
\hline \multirow{2}{*}{ Colour change $(\Delta \mathrm{E})$} & $\mathrm{T}_{1}$ & $36.37 \pm 0.01$ & $35.87 \pm 0.02$ & $37.09 \pm 0.05$ & $36.38 \pm 0.01$ \\
\cline { 2 - 6 } & $\mathrm{T}_{2}$ & $35.87 \pm .01$ & $35.76 \pm 0.01$ & $36.81 \pm 0.03$ & $36.36 \pm 0.04$ \\
\hline \multirow{2}{*}{ Titratable acidity (per cent) } & $\mathrm{T}_{1}$ & $0.69 \pm 0.05$ & $0.59 \pm 0.04$ & $0.62 \pm 0.04$ & $0.52 \pm 0.04$ \\
\cline { 2 - 6 } & $\mathrm{T}_{2}$ & $0.76 \pm 0.04$ & $0.67 \pm 0.05$ & $0.69 \pm 0.06$ & $0.61 \pm 0.06$ \\
\hline \multirow{2}{*}{ Ascorbic acid (mg/100g) } & $\mathrm{T}_{1}$ & $5.96 \pm 0.15$ & $4.02 \pm 0.15$ & $5.16 \pm 0.10$ & $5.45 \pm 0.12$ \\
\cline { 2 - 6 } & $\mathrm{T}_{2}$ & $6.6 \pm 0.26$ & $4.52 \pm 0.51$ & $6.13 \pm 0.11$ & $6.19 \pm 0.20$ \\
\hline \multirow{2}{*}{ Overall acceptability } & $\mathrm{T}_{1}$ & $7.38 \pm 0.86$ & $7.31 \pm 1.05$ & $6.55 \pm 0.88$ & $7.11 \pm 1.53$ \\
\cline { 2 - 6 } & $\mathrm{T}_{2}$ & $6.55 \pm 1.01$ & $6.94 \pm 1.23$ & $7 \pm 1$ & $6.66 \pm 1.22$ \\
\hline
\end{tabular}

$\mathrm{T}_{1}$ : Treated, $\mathrm{T}_{2}$ : Untreated; reported values are an average of 3 replications Values given in the Parenthesis depicts the standard deviation Significant value if the value is less than $=0.1 \%$ (Significant at $p<10$ per cent) than value is Significant.

If the value is less than $=0.05 \%$ (Significant at $p<5$ per cent) than value is Significant.

Table 5: Microbial count in dried garlic powder under different drying and packaging conditions

\begin{tabular}{|c|c|c|c|c|c|c|c|}
\hline \multirow{3}{*}{ Drying } & Days & \multicolumn{7}{|c|}{ Microbial load (cfu/g) } \\
\cline { 2 - 8 } & & \multicolumn{5}{|c|}{ Packaging material } \\
\cline { 2 - 8 } & & \multicolumn{7}{|c|}{$\mathbf{T}_{\mathbf{1}}$} & \multicolumn{2}{c|}{$\mathbf{T}_{\mathbf{2}}$} \\
\cline { 2 - 8 } & LDPE & PE & ML & LDPE & PE & ML \\
\hline \multirow{3}{*}{ Shade Drying } & 0 & 0 & 0 & 0 & $1.25 \times 10^{-6}$ & $1.25 \times 10^{-6}$ & $1.25 \times 10^{-6}$ \\
\cline { 2 - 8 } & 30 & $4 \times 10^{-5}$ & $4 \times 10^{-5}$ & $3.5 \times 10^{-5}$ & $4 \times 10^{-5}$ & $5 \times 10^{-5}$ & $4 \times 10^{-5}$ \\
\cline { 2 - 8 } & 60 & $8.5 \times 10^{-5}$ & $11 \times 10^{-5}$ & $7.5 \times 10^{-5}$ & $13 \times 10^{-5}$ & $19 \times 10^{-5}$ & $11.5 \times 10^{-5}$ \\
\hline \multirow{3}{*}{ Oven Drying } & 0 & 0 & 0 & 0 & $1.25 \times 10^{-6}$ & $1.25 \times 10^{-6}$ & $1.25 \times 10^{-6}$ \\
\cline { 2 - 8 } & 30 & $2 \times 10^{-6}$ & $3 \times 10^{-6}$ & $3 \times 10^{-6}$ & $4 \times 10^{-6}$ & $5 \times 10^{-6}$ & $3 \times 10^{-6}$ \\
\cline { 2 - 8 } & 60 & $5.5 \times 10^{-6}$ & $9 \times 10^{-6}$ & $4.5 \times 10^{-6}$ & $9.5 \times 10^{-6}$ & $14.5 \times 10^{-6}$ & $8.5 \times 10^{-6}$ \\
\hline \multirow{3}{*}{ Microwave Drying } & 0 & 0 & 0 & 0 & $1.25 \times 10^{-6}$ & $1.25 \times 10^{-6}$ & $1.25 \times 10^{-6}$ \\
\cline { 2 - 8 } & 30 & $3 \times 10^{-5}$ & $4 \times 10^{-5}$ & $3 \times 10^{-5}$ & $4 \times 10^{-5}$ & $4 \times 10^{-5}$ & $4 \times 10^{-5}$ \\
\cline { 2 - 8 } & 60 & $6.5 \times 10^{-6}$ & $10 \times \times 10^{-5}$ & $7.5 \times 10^{-5}$ & $10 \times 10^{-6}$ & $18.5 \times \times 10^{-5}$ & $10 \times 10^{-5}$ \\
\hline Solar Drying & 0 & 0 & 0 & 0 & $1.25 \times 10^{-6}$ & $1.25 \times 10^{-6}$ & $1.25 \times 10^{-6}$ \\
\hline
\end{tabular}




\begin{tabular}{|c|c|c|c|c|c|c|c|}
\hline & 30 & $4 \times 10^{-6}$ & $4.5 \times 10^{-6}$ & $3 \times 10^{-6}$ & $5 \times 10^{-6}$ & $6 \times 10^{-6}$ & $4 \times 10^{-6}$ \\
\cline { 2 - 8 } & 60 & $8.5 \times 10^{-6}$ & $12.5 \times 10^{-6}$ & $9 \times 10^{-6}$ & $12 \times 10^{-6}$ & $18 \times 10^{-6}$ & $12.5 \times 10^{-6}$ \\
\hline
\end{tabular}

$\mathrm{T}_{1}$ : Treated, $\mathrm{T}_{2}$ : Untreated; LDPE: Low density polyethylene, PE: Polyethylene, ML: Multilayer Reported values are an average of 3 replications Values given in the Parenthesis depicts the standard deviation. Significant value if the value is less than $=0.1 \%$ (Significant at $p<10$ per cent) than value is Significant. If the value is less than $=0.05 \%$ (Significant at $p<5$ per cent) than value is Significant.

\section{Conclusion}

It can be concluded on the basis of the results of the present experiment that most of the treatment combination of oven drying under Treated sample was found best for most of the physical parameters cutting strength (Texture analysis), moisture content $(\%)$, and rehydration ratio of dried garlic sample. The quality parameters (ascorbic acid, acidity and Colour, flavor, taste, and overall acceptability) of dried garlic powder were found best in shade drying under Treated sample. Microbiological parameters viz., Total viable fungal colony in different packaging material was found the best in multilayer packaging under treated sample. In different drying techniques microbial colony was low in oven dehydrated samples compared to different using solar drying, shade drying, and microwave drying techniques.

\section{References}

1. AOAC. Official methods of analysis of the association of official agricultural chemists, Association of Analytical Chemists, Washington, D.C, 1988.

2. Abbasi SB, Mowla D. Experimental and theoretical investigation of drying behaviour of garlic in an inert medium fluidized bed assisted by microwave, Journal of Food Engineering. 2008; 88:438-449.

3. Avila GT. Post-harvest management in bulb-producing vegetables. Conditions for the artificial drying of garlic. Avances-en-Horticultura. 1998; 2(1):25-35.

4. Baysal T, Icier F, Ersus S, Yildiz H. Effects of microwave and infrared drying on the quality of carrot and garlic. European-Food-Research-and-Technology. 2003; 218(1):68-73.

5. Bondre SV, Sonkamble AM, Patil SR. Effect of different packaging materials on quality of garlic powder. International Journal of Processing and Post-Harvest Technology. 2016; 7:121-125.

6. Choudhary B, Flores AF. Chemical constituents of garlic Vegetables National Book Trust, New Delhi (India), 1979, 103-105.

7. Casado FJ, lopez A, Rejano L, Sanchez AH, Montano A. Nutritional composition of commercial pickled garlic. European Food Research and Technology. 2004; 219(5):355-359.

8. Figiel A. Drying Kinetics and Quality of vacuummicrowave dehydrate Garlic Cloves and Slices. Journal of Food Engineering. 2009; 94:98-104.

9. Flores AF. Anales fac farm.Y bioquim. Univ nacl. Mayor. Sen. Marcos (Lima, Peru). 1954; (2):229-233.

10. Krokida MK, Maroulis ZB. Effect of microwave drying on some quality parameters of dehydrated products. Drying Technolo. 1999; 17:449-466.

11. Lews JA. Garlic the one for all remedy. Spices India, 1991, 8-12.

12. Le Magar, Jelen. Food engineering and process application. Trans, Phenomena (New Yark: Elserier appl. Sci.), 1986.

13. Madamba PS, Driscoll RH, Buckle KA. The thin layer drying characteristics of garlic slices. Journal of food Engineering. 1996; 29:75-97.
14. Mayer L, Sere Ho AM. Modeling shrinkage drying connective drying of food materials. J. Food Process Eng, 2004, 373.

15. Pruthi JS. Composition of garlic. Minor spices and condiments crop management and Post-Harvest Technology. 2001: 97-104.

16. Rathore NS, Mathur AN. Design and development of solar tunnel dryer for drying Di-basic calcium phosphate (DCP). J Agric. Res. 2001; 7:33-39.

17. Ranganna S. Hand book of analysis and quality control for fruit and vegetable products. 2nd edn. Tata McGraw Hill Publication Co. Ltd., New Delhi, 1986, 112.

18. Sharma PK. Dehydration characteristics of ten garlic cultivars. J. Food Sci. Technol. 1993; 28:348-351.

19. Thompson HC, Kelly WC. Vegetable Crops. McGraw Hill Book Co. Inc., New York, 1957, 368-370. 